\title{
Simulation-Based Decision Support Tools in the Early Design Stages of a Green Building-A Review
}

\author{
Tian Han, Qiong Huang *, Anxiao Zhang $®$ and Qi Zhang \\ School of Architecture, Tianjin University, 92 Weijin Road, Nankai District, Tianjin 300072, China; \\ hantian_tju@163.com (T.H.); zhanganxiao9012@gmail.com (A.Z.); zhangqi_arch@vip.163.com (Q.Z.) \\ * Correspondence: qhuang@tju.edu.cn; Tel.: +86-186-0265-8127
}

Received: 5 September 2018; Accepted: 12 October 2018; Published: 15 October 2018

check for updates

\begin{abstract}
Early simulation work in the decision-making stage faces several challenges, including, for example, rapid changes of design, input variable uncertainties, and the lack of design information, although early design work represents a large percentage of energy saving potential. The availability of simulation tools for early design stages can help the architect analyze more alternatives. In this study, the existing simulation tools were explored and classified into three categories: simulation plugins based on the design software, geometry user interfaces for a simulation engine, and self-governing simulation tools. Each category's typical tools were illustrated with their use, and a uniform standard comparison was conducted to screen tools that are available in the early design stages. The future trends of simulation tools are discussed in the second part: building databases based on existing knowledge, uncertainty and sensitivity analyses, and optimization. Time-consuming simulation is a problem in the use of simulation tools in early design stages. Advanced techniques were developed in this part for fast computing, i.e., cloud computing, parallel computing, meta-models, and more statistical methods. This paper illustrates the practical application of particular simulation tools in the early design stage, presents their limitations, and discusses decision-support tools for specific building design activities.
\end{abstract}

Keywords: building performance; early design stage; decision-making tool; energy efficient design

\section{Introduction}

In the 21st century, when advocating sustainable development, the architect must gradually transform from the traditional high consumption development pattern to the efficient green development pattern. The traditional design methods are gradually replaced by new performance-based methods in which simulation tools are highly applied to support decision making [1]. There are many simulation tools, such as EnergyPlus, ESP-r, and TRANSYS. However, most of these tools are aimed at the late design stages for very detailed simulations [2]. In contrast, there are far fewer decision-support tools for the early design stages. Studies show that green building performance-optimization pathways are almost always determined in the early design stages. More than $40 \%$ of energy-saving capacities come from the earlier planning stage. However, through a survey of 76 green buildings in Europe (using 303 green building technologies) [3], Dr. P. de Wilde of the Delft University in Belgium found that $57 \%$ of the technical measures were considered in the earlier planning stage.

Actually, designing with building simulation feedback in the early design stage has existed since the initial stage of computer modeling [4]. However, when realizing decision making in the early design stage, many challenges should be solved, for instance, time-consuming modeling, rapid changes in the design, conflicting demands, input uncertainties, and calculation space. In addition, building design is a multi-partner discipline in which decision-making is influenced by architects, engineers, contractors, 
and building owners [5]. Multidisciplinary communication is needed to realize multiple-goal design results that not only include energy simulation but also, for example, the indoor environment, environment pollution, carbon emission, and lifecycle cost. This paper presents energy-oriented software tools that support decision-making in the early design stages.

In the green building design-software field, there are primarily two types of tools. One type is design tools, such as SketchUp, Revit, and Rhino. The other type is simulation tools, such as EnergyPlus. In addition, there are derivative software and simulation plug-ins based on the mainstream software. This paper introduces the tools' application conditions in three categories according to their simulation principles. The categories are plugins for design tools, GUIs based on simulation engines, and self-governing simulation tools. A uniform criterion comparison is provided concerning the mentioned tools to illustrate further what simulation tools are available in the early design stages for decision making. A few future trends in support tools are presented in the following order: building templates and database, uncertainty analysis and sensitivity analysis and optimization, all of which are topics of interest in articles about decision-support tools. Time-consuming questions are discussed through solutions such as computing and meta-models. Furthermore, support tools for specific building design activities are mentioned in this paper.

\section{Categories of Simulation Tools}

Currently, many tools and methods exist for building performance simulations; various functions of different tools are used for specific simulation purposes. In addition, a popular hybrid use of two types of tools or a hybrid use of a simulation tool and method is used for multi-objective simulation work [6]. In several study research frameworks, many authors focus on decision making in the early stage of building design. This paper primarily sorts out and analyzes the popular software in the market, methods for early simulation and other small-scale methods that apparently support decision making in the early design stages according to the design principles and ideas of software classification, followed by a review of different software studies.

Software descriptions will be organized in the following three classifications: (1) Simulation plugins for popular CAD tools. These tools were organized as plugins for popular design tools. Some of them are coupled with outside simulation engines, e.g., EnergyPlus or DOE. Some of them can calculate with their own simulation algorithms. The structure of these tools is shown in Figure 1. Geometry design tools such as SketchUp, Rhino, and Revit are widely used by designers. Based on large-scale usage, plugins for popular design tools developed by researchers will be more easily accepted by users. For example, plugins for SketchUp include OpenStudio, Sefaira, and HTB2. (2) GUI for mature simulation engines. Because of the difficulty that common users can have operating a simulation tool such as EnergyPlus, researchers developed a series of geometry user interfaces. The aim is to help the user complete a simulation under a concise and visualized interface. The structure is shown in Figure 2. There are many tools in this structure. For example, DesignBuilder and N++ are based on EnergyPlus, and the optimization tool Beopt is based on DOE2 and TRNSYS. (3) Self-governing simulation tools. This type of tool can operate in its own simulation engine, module interface or calculation method, such as MIT advisor. The structure is shown in Figure 3.

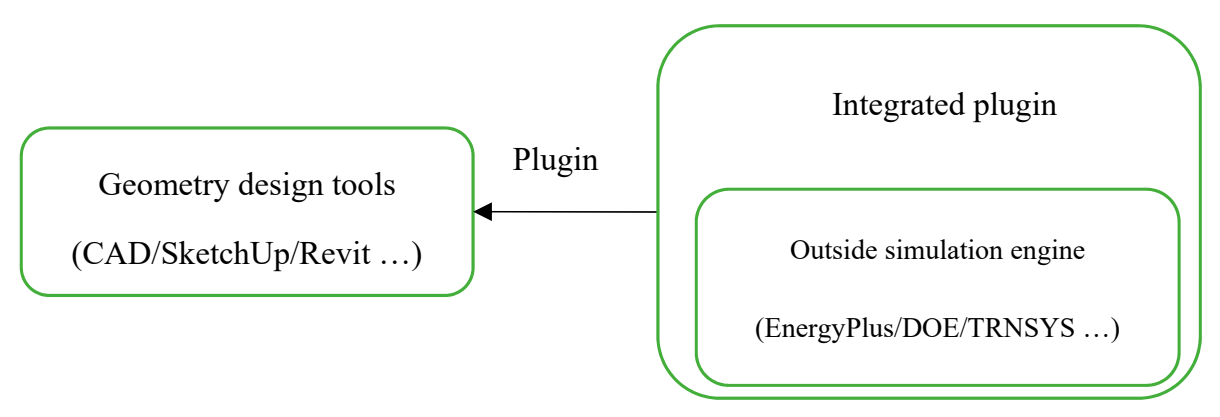

Figure 1. The simulation plugin for design tools. 


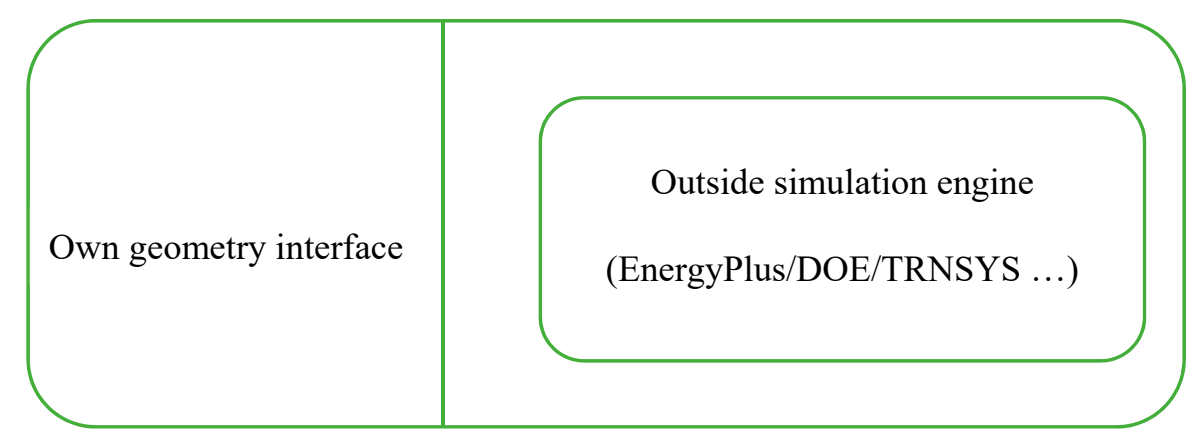

Figure 2. The geometry user interface for a simulation engine.

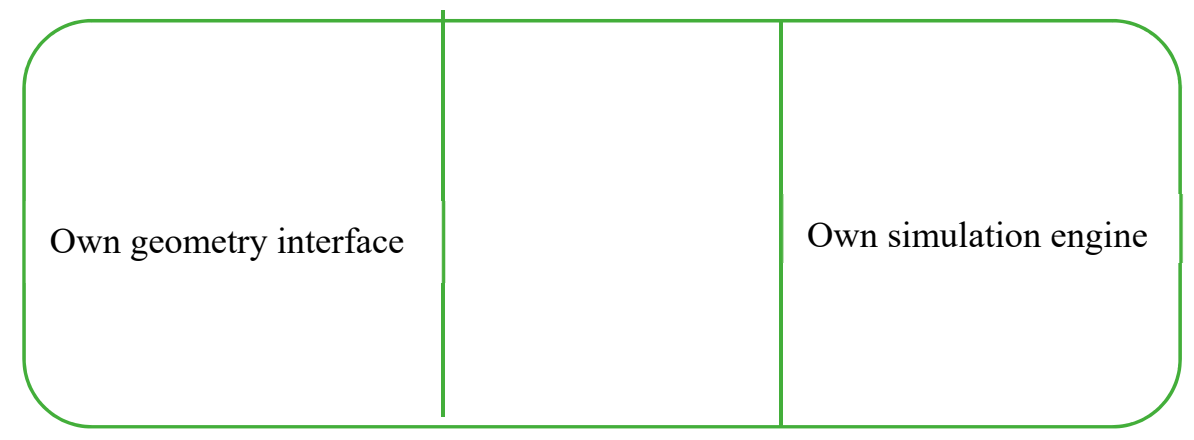

Figure 3. The self-governed simulation tools.

\subsection{Plugins for Design Tool}

This paper illustrates a few plugins in this part; all of them are plugins for design tools in building design. SketchUp, Revit, and Rhino are mentioned as design tools. Although they are developed for different markets, the functions of design and simulation can be realized when utilizing their plugins. Most plugins are coupled with outside simulation engines to complete specific simulation tasks. The framework of simulation plugins for design tools is shown in Figure 4.

OpenStudio [7] is a suite of free and open-source building-energy simulation tools for building design. OpenStudio supports the entire building energy simulation based on EnergyPlus and advanced lighting analysis based on Radiance, thermal comfort, air condition and lifecycle costs (LCC). OpenStudio includes graphical interfaces along with a software development kit (SDK) for constructing a building energy simulation [8]. Its primary application is as a plugin for SketchUp. OpenStudio was designed to cooperate with SketchUp, allowing architects to simulate before construction. OpenStudio organizes a parametric energy simulation process based on its several tools. D.L. Macumber et al. [9] illustrate this process using the Parametric Analysis Tool in detail, in which cloud computing helps to analyze parameters and energy simulation. M. Picco et al. [10] introduced a simplification methodology for commercial building models around the optimization of energy efficiency in early-stage design. They built a large multi-story office building with detailed information through the OpenStudio software. Then they analyzed the detailed model and progressively simplified it. At each simplification step, a comparison between the detailed model results and the simplified model results was given to ensure the quality of the results of the simplified model. Their research aims to meet the time requirements and to maintain a received level of correctness of results. OpenStudio usually needs many detailed parameters to build energy models. Therefore, it is more suitable to be used in the late design stages. However, E. Boxe et al. [11] presented an improved theory to support decision-making with OpenStudio. They coupled OpenStudio with an uncertainty and sensitivity analysis method to quantify the parameter sensitivity for the most optimal sampling results, which can support decision making. 


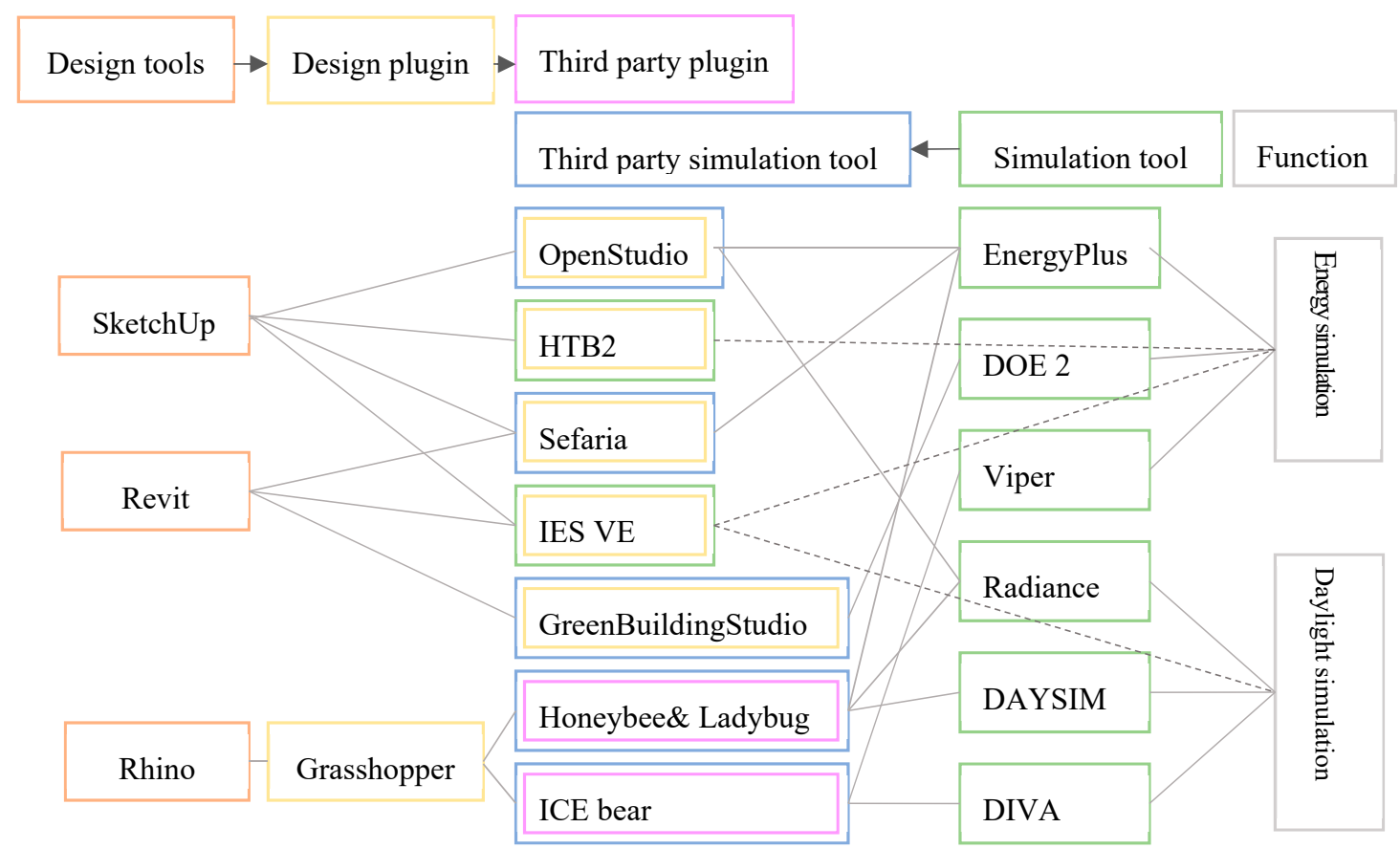

Figure 4. The framework of the simulation plugin for the design tool.

P. Jones et al. [12] introduced a plugin-HTB2 (Heat Transfer in Building: version 2) based on SketchUp-aimed at building energy consumption at an early design stage. HTB2 was developed as two processes within an intensive computational framework. One process involves the modeling of multi-building scale development. The second involves a trade-off between multi-parameter options for a single building type. For single-building modeling, HTB2 can perform a parametric analysis at the early design stage with millions of data items. The results can be referred to by A post-processing "sensitivity tool" to help designers make decisions. They [13] also present an energy-modeling framework based on this tool and its sub-models to simulate the SOLCER house. The sub-models are developed based on HTB2 for the thermal system, i.e., the Transpired Heat Recovery (TSC) and Mechanical Ventilation Heat Recovery System (MVHR). The authors compared simulated data by sub-models and measured data, which indicates the higher accuracy of sub-models for a thermal system. Variation exploration in the design of the SOLCER house can be realized with this modeling framework now. D.K. Alexander et al. [14] modified and tested this HTB2 tool for the calculation of glazing and shading options. They developed and selected an algorithm to enhance the calculation accuracy of a glazing system, which can be provided for selection for multiple glazing options at different design stages.

IES $<$ VE $>$ [15] is a building performance simulation and analysis tool designed by Integrated Environmental Solutions in England. IES VE is aimed at the entire process of building design, which integrates several blocks to realize the entire performance simulation of a building computationally. IES VE has a visible modeling block, permitting users to create a model directly in the IES VE modeling window. In addition, IES has developed plugins for Revit, SketchUp, and CAD, allowing interconnection between CAD and BIM by files, which simplifies users' modeling operations. With this software, different operators can collaborate and communicate with each other using the same platform at different stages of the overall process. This software allows Ecotect to read IES files and helps architects to simulate models in an early design stage. However, this tool itself is more commonly applied in later detail design and management stages.

Green Building Studio (GBS) [16] is a simulation tool for an entire building's energy built on Autodesk. It helps architects and designers to realize an entire building energy analysis, energy consumption optimization and carbon-neutral design in the early design stage based on a web 
energy-analysis source. GBS simulates building energy based on the DOE-2.2 engine and, at the same time, creates accurate input files for EnergyPlus for interoperability. GBS software creates a one-step simulation process in which GBS creates a complex and integrated energy model through reading from Revit and Vasari with minimum sets of inputs because GBS has stored default building model information [17]. Based on the GBS tool, S.H.E. Lin and D.J. Gerber [18] proposed a framework for evolutionary energy performance feedback for design (EEPFD), which supports early decision making and rapid design iteration through parametric analysis, automation, and multi-objective optimization. There are six steps in the EEPFD process for integrating design and energy simulation. The process uses Revit to design and model, GBS to analyze energy performance and H.D.S. Beagle to evaluate results. In this EEPFD process, an integrated, iterative and decision-supported design workflow can be realized.

Grasshopper is a parametric design plugin for Rhino. Parametric design tools provide more alternatives for building design in the early design stage. Such parametric scripting tools overcome the obstacles of expertise with the simulation tool, simplifying or reducing tools' and interfaces' professional levels. An increasing number of parametric design tools are being utilized in building design and studies [19]. Similar to Grasshopper, other parametric tools include Dynamo [20], a plugin for Revit and stand-alone software Generative Components [21]. This article introduces plugins for grasshopper and the third-party plugins for Rhino, which can help designers to complete performance simulations and to support decision making. E. Elbeltagi et al. [22] raise a visualized strategy for building parametric analysis in the early design stage. The strategy is an energy-oriented workflow aimed at the climate in Egypt. Through Rhino, Grasshopper and its plugins couple a parametric design tool and an energy simulation tool to construct a building energy-consumption database. These two types of tools' parallel cooperation can visualize the energy model database and help an operator to evaluate building performance in a more flexible manner.

In addition, Ladybug [23] is an open source environmental analysis plugin, permitting users to import standard weather files (.epw) into Grasshopper. This plugin will analyze weather conditions for a building's location and provide a plethora of weather metrics in 3D graphics. Coupled with Ladybug, Honeybee [23] is a good plugin supporting performance simulation. Honeybee connects several building performance simulation (BPS) tools (EnergyPlus, Radiance, DAYSIM, and OpenStudio) to the grasshopper platform; thus, it can operate a simulation process because these BPS tools can achieve energy simulation and daylighting analysis [24]. Furthermore, together with genetic algorithm block Galapagos in grasshopper, an optimization process-based performance will be realized. M. Qingsong and H. Fukuda [25] used Honeybee, Ladybug, and the Galapagos Evolutionary Solver to maximize the usefulness of daylighting and minimize energy consumption by optimizing an office building's openings. Honeybee and Ladybug will help designers with parametric designing and even optimization, but Galapagos running with BPS plugins at the same time will give the computer many calculation options and supply the time costs needed in this process. T. Østergård et al. [26] mentioned that Rhino supplies no detailed design, and Honeybee cannot achieve parametric analysis and detailed performance simulation. Thus, the final design models and simulation results should be completed in detailed CAD and BPS tools through data interoperability translation from a preliminary to detailed design.

Another plugin for grasshopper is Mr.comfy [27], a visualization suite that can visualize the simulation results and display them in the Rhino modeling window. Different from other plugins for displaying chart or graphical data, Mr.comfy addresses energy consumption, comfort, illuminance, and any other available report variables as color-coded surfaces and directly displays them in the corresponding building spatial plan in which they occur. Mr.comfy does not operate the simulation itself; it only utilizes EnergyPlus and DAYSIM simulation results as a data source. Plugin ICE bear integrates indoor climate, daylight, and energy performance [28], and P.K.B. Lauridsen introduces an automated simulation process in which DIVA-for-Rhino component calculates daylight and the viper component calculates solar gain. Then, all of the results from DIVA and Viper will be sent to ICE 
bear. The DIVA/Viper/ICEbear complex will realize performance simulations about indoor climate, daylight and energy performance. When coupled with the genetic algorithm component Galapagos, an optimization can be conducted.

Some simulation plugins were mentioned in this part. HTB2, Sefaira, and GBS are aimed at the early design stages. The characteristics of these plugins are fast computing, few inputs, and rough estimation, which are sufficient and timely for decision making in early design stages. IESVE and OpenStudio are available for the overall building simulation. In addition, there are researchers who realize decision making through simplifying or coupling with sensitivity or uncertainty tools based on OpenStudio. The Rhino and grasshopper platform aim at geometry design and an ordinary parametric setting. Therefore, it is popular and convenient for designers to use in the early design stages.

\subsection{GUIs Based on Simulation Engines}

Another category of simulation tools is graphic user interfaces (GUIs) based on simulation engines. A list of simulation tools is developed based on existing and mature calculation engines, which can expand the existing functions and simultaneously meet the required result accuracy. Some BPS tools and their third-party BPS tools are listed in Table 1.

Table 1. The lists for some BPS tools and third-party BPS tools.

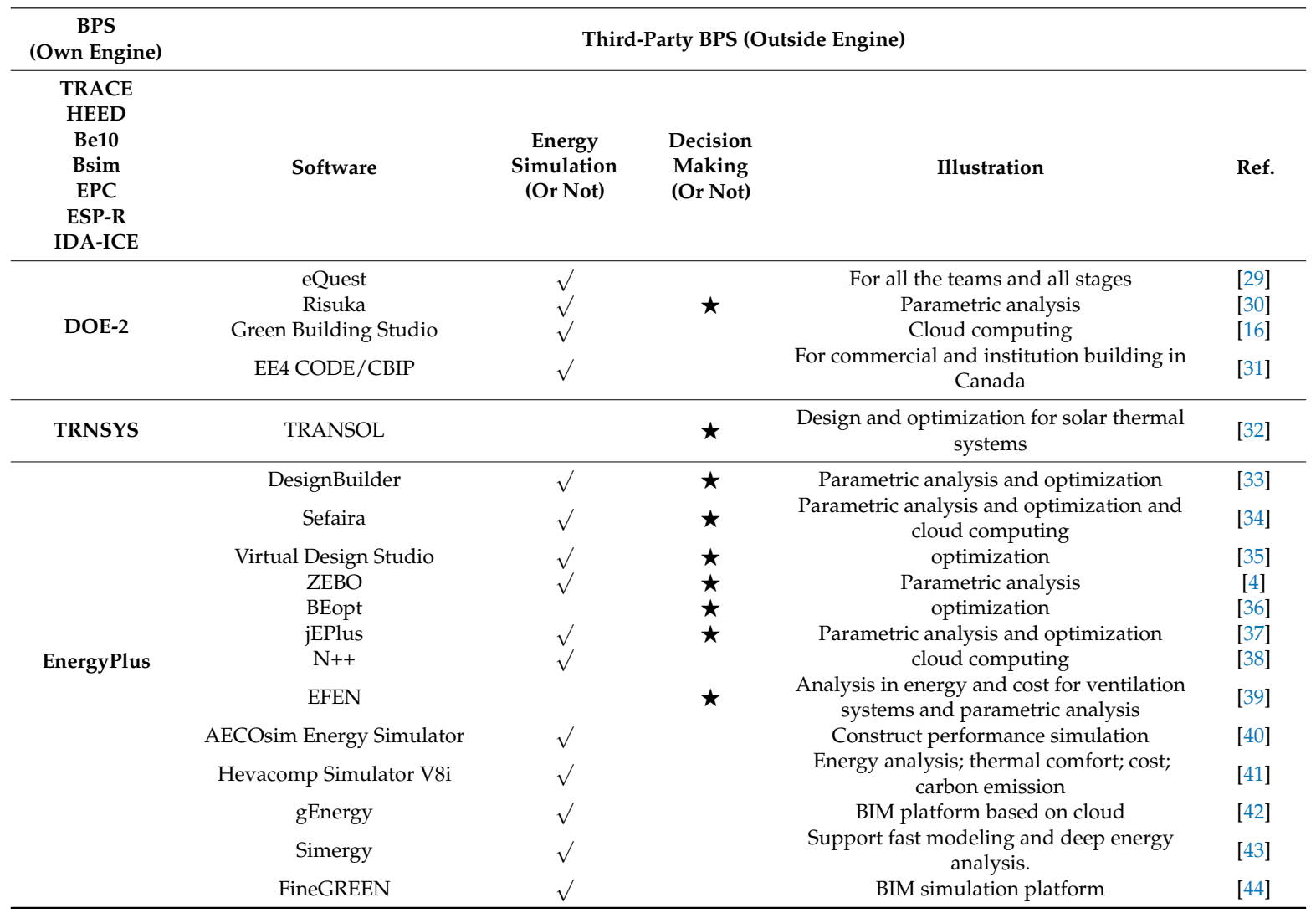

DesignBuilder [33] is a visual modeling tool for overall building performance-simulation software based on the EnergyPlus engine. DesignBuilder has its own modeling window and permits model image visualization. In addition, a geometry model can also be imported from SketchUp or Revit through specific plugins or files. DesignBuilder has a large amount of building model information data. When the building type is selected, the corresponding default settings will be extracted to construct an energy model to allow architects to analyze factors that influence energy consumption such as spatial form, plane layout, and window-to-wall ratio. This software remains under development; two blocks on Parametric Analysis and Optimization have been used for real design. A. Zhang et al. [45] organized 
an integrated method for school and schoolyard design in northern China through the hybrid use of DesignBuilder and a three-dimension microclimate tool, ENVI-met. In their suggested process, the tool ENVI-met completed the outdoor climate calculations, which were imported to DesignBuilder as boundary conditions. Moreover, DesignBuilder was responsible for analyzing the cooling demand for the school design. The entire workflow involves different building design aspects to promote the school design's evaluation and optimization.

jEPlus [37] is a specialized use of EnergyPlus to perform complicated parametric analysis [46]. It creates a graphic user interface in which the user can define design parameters, edit models, manage simulation runs and display results. jEPlus's data structure makes it highly suitable for optimization purposes [47]; thus, this software can create millions of simulation cases in a few minutes. JESS was created based on jEPlus, which can accept user requests and run an EnergyPlus simulation on a remote server. It is a connection tool between jEPlus, EnergyPlus, and a backend database. JESS permits multiple simulation tasks to run simultaneously online. However, this software has a high threshold, requiring EnergyPlus modeling and scripting abilities. Therefore, it is aimed at consultants, engineers, and researchers who have large-scale simulation and deeper analysis needs. jEPlus and JESS can achieve sensitivity analysis, uncertainty analysis, optimization, and model calibration through importing EnergyPlus model and weather files.

$\mathrm{N++}$ [38] was developed by ExpertAPP and employs EnergyPlus to formulate a graphic user interface. This software's objects all follow the EnergyPlus object structure, allowing for the dragging and dropping of the main EnergyPlus objects. N++ has an intuitive user interface, modeling interface and simulation result display window. This software supports architects, engineers and energy researchers, completing exploitation and management for energy models and even parametric analysis and optimization coupling with jEPlus and GenOpt.

P.M. Pelken et al. [35] introduced a software platform—“Virtual Design Studio (VDS)"—under development, to conduct building performance simulations. The tool is an integrated and optimized platform for building design and their energy and environment systems, which support multiple operator collaborations and the whole lifecycle design. For this software, researchers created a 3D matrix as a fundamental structure including multi-design teams, multi-design stages, and multi-design factors. Researchers consider the whole building design stage in this tool. In each stage and for each operator, the graphic user interface allows for an accustomed viewpoint according to the user's role.

S. Attia et al. [4] introduced a development tool named "ZEBO" that aims at decision support based on simulation results from early design stages of a zero-energy building. The tool is a conceptual model for Egyptian residential buildings, which is only available for tropical climates and particular cities in Egypt. Quick feedback can be realized to support decision making for it's based on an embedded benchmark model and database and lots of building energy data can be input as default values according to the selected site location and code. So this tool is also limited to its own library of generic rectangular single-zone with few alternatives for building inputs. Users can obtain a variety of alternatives after the tool's sensitivity analysis in a short time. For the later building design stages, ZEBO supports the interaction between tools with an established model.

M. Jokela et al. [30] introduced an integrated building simulation tool-Riuska. Granlund developed this tool, which covers the entire building lifecycle from the preliminary design to renovations. The purpose is building services design and facilities management. Riuska uses DOE-2.1E as its simulation engine for all stages, but the simulation results should be displayed in a form that can be understood by a non-expert. The main components of this software are the user interface, simulation database, result module, calculation engine, and a building geometry modeler (SMOG). The simulation database includes, for example, building data, construction, envelope, and systems, which can be used as defaults to build an energy model automatically based on the building type in the preliminary stage. The database can be shared and exchanged by multiple disciplines and multiple users. The user interface can be changed according to the users' knowledge and need. However, 
this software is quite old in years, and it is primarily oriented toward engineers for building services design and equipment management.

iDbuild [48] is an integrated thermal and lighting simulation tool based on the climate. It creates a design management process addressing performance requirements [49]. In this process, when the simulation results do not meet the desired performance, users can distinguish the different parameters' influence on energy consumption, indoor environment temperature, air quantity, and indoor daylighting condition through parametric simulation. Thus, designers might easily change a design proposal, simulate it again, and find a better combination of design options closer to the performance requirements. iDbuild realizes thermal analysis based on Building Calc [50,51] and lighting analysis based on Light Calc [51]. In addition, S. Petersen and S. Svendsen [52] advanced a method of informed decisions in the early stages of building design based on iDbuild. The proposed expansion of building design workflow iteratively increased in two steps- "parameter variations" and "informed design proposal". These increased operations can be realized in iDbuild. A case study shows the tool's ability to analyze parameter variations. Thus, iDbuild can be used for parameter variations generating an overview of how performance-decisive parameters affect performance requirements. For Building Calc, T.R. Nielsen [50] introduced a simple tool that can assist in early design stages with energy simulation and indoor thermal comfort evaluation. Because very few inputs can provide hourly data for evaluation, there were more possibilities for using this older tool. However, it only supplies a rough estimation of energy and thermal comfort. Light calc was mentioned by S. Petersen et al. [51]. The authors described a simple combination of ray tracing, the luminous existence method, and the concept of the urban canyon method to present the effect of the urban canyon on the daylight level and energy demand in the early design stages. They integrated that method with the Building Calc and Light Calc tools to perform light and energy simulation rapidly.

Different from energy simulation tools, some tools were designed for specific parts of a building, e.g., building facades or building fenestration. These building components usually have a great influence on the entire building's energy consumption, which will be determined in the early design stages. Therefore, architects usually spend much energy analyzing alternatives for facades or fenestration in the early design stage. Aiming at this stage, C.E. Ochoa and I.G. Capeluto [53] suggest an advice tool, "NewFacades", for intelligent facades based on energy and visual comfort in the early design stages, which can provide smart facade combination alternatives. This tool forms a building geometry model through a list of text inputs, including, for example, building principles, location, orientation, type, and surroundings. NewFacades provides detailed and comparative energy and visual comfort evaluations for each alternative by integrating the energy modeling engine, EnergyPlus. Furthermore, because the tool focuses on the conceptual stage, the output from NewFacades can commonly be used in more-advanced design stages in an EnergyPlus-compatible format. Thus, smoother connectivity for building design processes can be realized based on different tools' interoperability.

In building facade design, fenestration design usually represents a key point in energy consumption. W. Bustamante et al. [54] introduced a simulation tool integrating thermal and lighting to support the fenestration of system design. This integrated tool, named mkSchedule, focuses on complex fenestration systems in office buildings. It integrates Groundhog (a SketchUp plugin), Radiance, and EnergyPlus respectively for building a space model, lighting simulation and thermal simulation. Under indoor lighting comfort criteria, mkSchedule can allow for the most irradiance to reduce energy consumption. In addition, J.H. Oh et al. [55] presents guidelines and tools for window development in early-stage decision support. The suggested window design guideline includes three parts: a downloadable document file, a web application-COMFEN and a stand-alone tool. The webpage tool can perform a complete perimeter zone evaluation and compare alternatives for up to 4 cases, aiming to present the pre-simulated energy consumption result. Using visual basic for applications and jEPlus, an easy-to-use Microsoft Excel interface can help to conduct the entire whole 
building simulation. This tool can explore recommended alternatives through regression models, which can assist architects with multiple decision alternatives.

Trading off building's windows, facades, layouts, and shading is the main task in the early stage of building design. Architects can determine specific shading alternatives or facade options with the help of simulation tools. However, this type of tool should have a good interoperability with other tools to support further design and simulation in the detail stages.

A list of GUIs was mentioned in this section. Some of them support the entire lifecycle of building design, e.g., DesignBuilder, N++, VDS, and Riuska. DesignBuilder is more useful in the early design stages when adding expanded functional blocks-Parametric analysis and Optimization. Some of the tools are designed for parametric analysis and optimization itself, e.g., jEPlus and iDbuild. In addition, there is a simulation tool aiming at the early design stages-ZEBO-in which the minimal inputs and rough estimations are helpful for decision making. The other tools mentioned support decision making regarding specific parts of a building; e.g., NewFacades supports intelligent facades, and mkSchedule supports complex fenestration systems.

\subsection{Self-Governing Simulation Tools}

The third category was self-governing simulation tools with their own calculation algorithms and geometry user interfaces. Many early simulation tools can be classified into this category, e.g., TRNSYS. An early self-governing tool was mentioned in this article-MIT advisor.

B. Urban and L. Glicksman [56,57] present a simplified software tool for architects to assist in making decisions at the early-stage design of energy efficient buildings. However, it is not available in the detailed stage. The MIT design advisor limits the numbers of input parameters, with only some important parameters being permitted. Thus, users can obtain feedback from the software simulation quickly. This software is aimed at simulating different design elements and identifying their influence on energy consumption and human thermal comfort rather than at obtaining the final energy performance result. After finishing user inputs and importing weather data, the MIT design advisor presents the results in a graph, including energy, lifecycle, thermal comfort and daylighting. Because of the website-based simulation, it is rapid, making it a very good decision-making tool for some small-building design cases.

\section{Comparison of Simulation Tools}

The software description part in chapter two introduced several typical and common tools under three categories. Comparisons of these tools on interoperability, simulation results and function are displayed in Table 2. In this table, there is a star rating of the tools' availabilities in the early design stage. ( $\star \star x$ means poor for early use, and $\star$ means good for early use; the more $\star s$, the stronger is usability in early stages.) Evaluation of usability in early stages was conducted based on the following aspects:

1. The software must be architect-friendly.

2. The software can complete simulation and feedback work with few inputs.

3. The tool can support parametric analysis.

4. The tool supports the comparison of multiple alternatives.

Of these four criteria, 1 and 2 are mandatory standards; 3 and 4 are extra standards.

Criterion 1: The software must be architect-friendly. This point was evaluated based on the ease of operation, which includes, for example, convenience or lack thereof in operation, expertise threshold in the working process, and clear or unclear operation steps. As the main users in the early design stage, architects need continuities in the design process and design feedback. Therefore, a tool that is clear in its process, easy in operation, and has a low threshold of required knowledge can be more easily accepted by architects. For example, OpenStudio has high-expertise commands in the late parametric setting process, which is more suitable for use by professional engineers and designers. If this tool 
were used in the early design stage, it very likely would interrupt the architects' thoughts because of the number of professional parametric settings.

Criterion 2: The software can complete simulation and feedback work with few inputs. This point is essential in the early stage. Because architects know little about design parameters in the early stage, they need a tool to accomplish simple simulation assignments or design feedback with few inputs, which can be realized with the help of a benchmark or meta-model (this approach will be illustrated in detail in Section 4.1). A benchmark includes typical buildings' common energy parameters. An integrated simulation can be done when the user chooses building type and changes few or no energy parameters. Then, architects can analyze the simulation results of different alternatives. For example, DesignBuilder includes several building templates. After finishing the geometry modeling, the user can achieve a simple simulation and obtain feedback results only by changing the building's template. Of course, the user can change any energy parameters at any time according to their design goal with the help of the building database.

Criterion 3: The tool can support parametric analysis (PA). Computational assistant architecture design is an iterative process in a "Design-Simulation-Feedback-Design" cycle. An important function for early simulation tools is to give feedback information to architects, which is helpful to change alternatives and realize a low energy building design. The feedback information includes not only simulation results but also a sensitivity analysis, uncertainty analysis, or another type of parametric analysis and even optimization realized by the extended module. (There will be a detailed illustration in Sections 4.2 and 4.3). When facing numbers of parameters, architects usually determine parametric ranges through their own experience and judgment. However, when a parametric analysis package and optimization package are attached to a simulation tool, this parametric decision process can be completed by computer. The computer can not only increase the design speed but also decrease energy consumption in a low energy building design after a performance-oriented decision-making process with the support of appropriate techniques. For example, HTB2 has a parametric analysis package that can analyze multiple parametric influences on the final energy consumption and decrease the parametric numbers that must be determined by architects.

Criterion 4: The tool supports the comparison of multiple alternatives. At the beginning stage, because of design uncertainties, architects usually have many design alternatives. If a simulation tool permits the comparison and selection from among multiple alternatives, it will lower the difficulty of the alternatives' decision-making process. For example, ZEBO can display multiple alternatives simulation results in one user interface. This visualized result comparison is sufficiently simple to support a decision by users; it also simplifies the architects' operation-modeling many times and simulation many times to yield a better alternative. 
Table 2. The software comparison in interoperability, results, functions, etc.

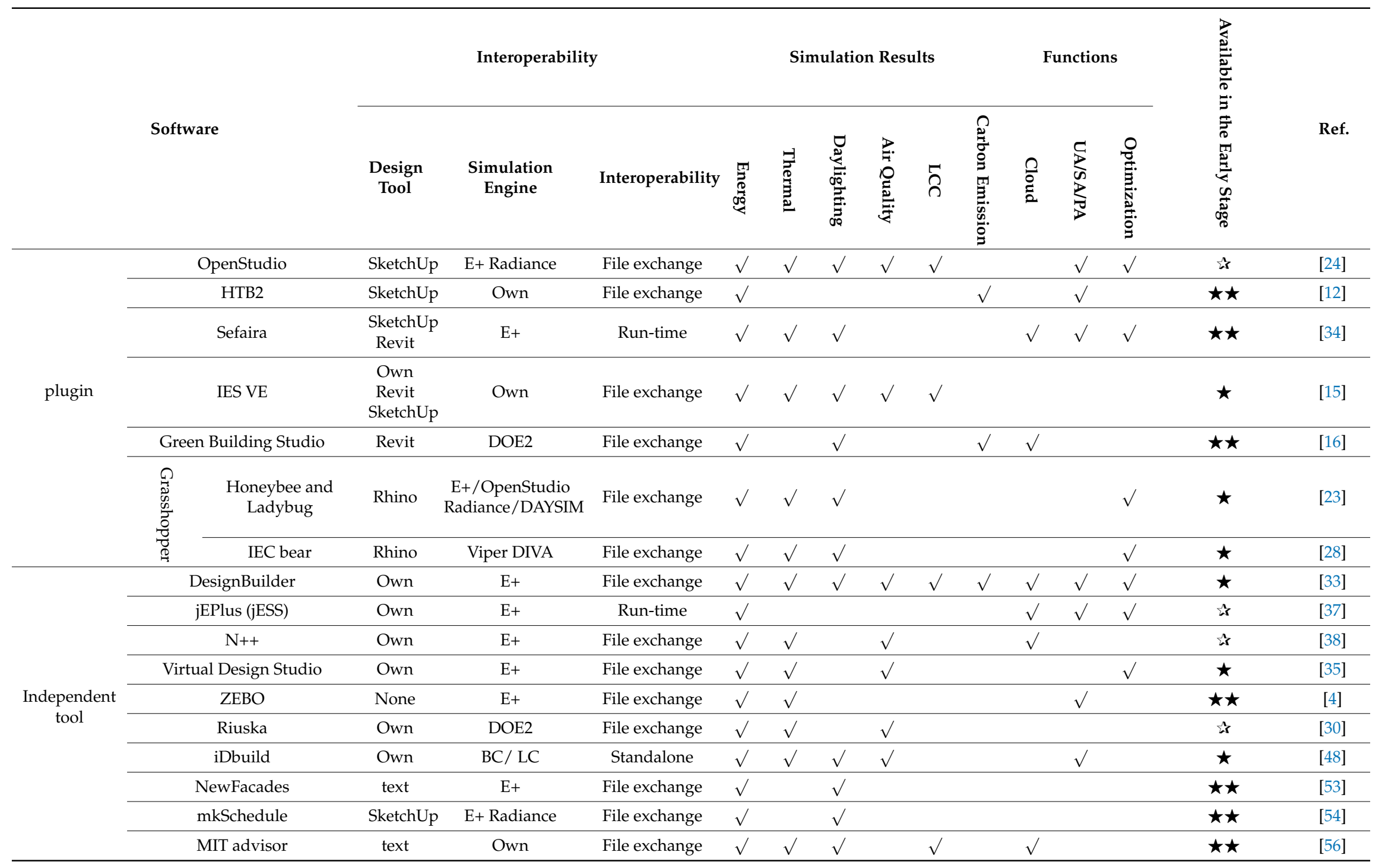




\section{Discussions}

The second and third parts of this article described and compared several recent popular building simulation tools. Some of them were designed for the early design stage, for example, Sefaira, which was designed as a plug-in for SketchUp, satisfying architects' need for continuity of design. Furthermore, run-time simulation feedback and cloud computation features are helpful for decision making. IES VE is a tool for the entire design process and can be applied in the early design stage with the help of Ecotect. However, some tools are not available in the early design stage, such as OpenStudio, which perhaps has many users. Although it has a plug-in for SketchUp, all of the modeling processes should be operated under the control of its plug-in. Even in the late stage, the required level of parameter-setting expertise erects a high threshold for architects. Therefore, a good decision-support tool must be "architect-friendly". In the early design stage, building information is non-integrated and only a very small number of variables are determined. Decision-making tools have increasingly been developed in next few aspects to realize simulation and feedback in early design stages: (1) Building templates and database; (2) Sensitivity analysis and Uncertainty analysis; and (3) Optimization. The ultimate goal of these tools is supporting decision making in the early design stage and illustrating the energy influence of design elements such as orientation, block, spatial form, and window wall rate. However, there are also limitations in simulation tools, for example, time-consuming questions, particularly in the process of optimization. To reduce the time needed, techniques such as Cloud computing and parallel computing have developed good simulation models. Moreover, statistical models can realize instant feedback compared with physical models.

Building templates and databases were built based on existing empirical building data in simulation tools and effectively solves the problem of early models lacking parametric information. Sensitivity and uncertainty analyses are targeted at building parameters; these analyses can identify parameter uncertainties and the degree of sensitivity to specific objective functions. Optimization can provide a series of optimal alternatives' combinations under defined functions. It is a more automated and an advanced technique for decision making.

\subsection{Building Templates and Databases}

Building templates consist of a building library that includes several specific types of buildings with all of the building energy-model information. A few inputs needed for users and other model information will be provided as default values to realize a fast simulation. For example, ZEBO [4] designers used a simulation benchmark to represent high-density apartments in Egyptian cities. Recommendations of the Egyptian Residential Energy Standard will be used to supplement the energy model once the building's site location and type are selected. L. Wen and K. Hiyama [58] investigated the input conditions of 10 simulation tools, which are divided into three categories: design index, simple analysis program, and BIM relevant program. They found the largest obstacle to constructing an energy model database is the absence of effective energy parameters. They developed a good method to reuse the existing building database model to overcome this obstacle. These experience and design-guideline databases make up a building performance template.

In an article comparing ten different simulation tools [59], the authors organized users to vote for the "architect-friendly" simulation tools; the most popular tool was IES VE. One of the popular reasons is its templates, which permit a quick simulation in the early design stage. Another typical tool is DesignBuilder [33]. This software includes different types of building templates. Each template with all types of building information includes, for example, the normal materials, schedule, environment, and lighting. When the specific building template is selected, the corresponding building information is brought from the database and simulated directly in the early design stage. Of course, users can exchange any variables in any stage of their design from the building database library, which can benefit architects researching specific design elements, e.g., energy influence studies about different block forms under the same building template. 


\subsection{Uncertainty Analysis and Sensitivity Analysis}

Because of the lack of information in the early design stage, there are many uncertainty elements in building performance simulations. Uncertainty analysis (UA) about building simulations has been investigated by researchers for many years [60]. Sensitivity analysis (SA) is usually conducted followed by UA to identify parameters' influence on the goal results. In addition, some simulation tools have a functional block named "parametric analysis", which is a useful methodology for architects to make trade-offs between parameters, e.g., DesignBuilder and OpenStudio. Moreover, some tools were designed as "parametric analysis tools" [61] for analyzing parameters in early design stages, e.g., jEPlus. In this process, architects will weigh, compare, and then focus on a few crucial parameters, identify input parameters with the highest effect on building performance and control them in a proper range for low energy consumption. Parameters requiring weighing not only include geometry parameters, e.g., building scale, orientation, block, and window wall rate, but also parameters in the later stage, e.g., wall types, roof types, and glass types [22]. Thus, architects can obtain the parameters' influence on energy without waiting for the final simulation result. Relative to optimization, a parametric analysis needs fewer resources and calculations and will be faster and more suitable in the early design stage [4].

\subsubsection{Literature Reviews about UA and SA}

J. Chen et al. [62] conducted an uncertainty analysis of thermal comfort in a prototypical natural ventilated office building. They organized UA elements into five dimensions: meteorological uncertainty, urban uncertainty, building uncertainty, system uncertainty, and occupant uncertainty according to the spatial scales. The authors then quantify their uncertainties followed by SA to avoid overheating risks in a naturally ventilated office building. H. Shen and A. Tzempelikos [63] performed UA and SA in a private office building with automated shading on daylighting and energy performance. They analyzed parameter uncertainties based on a Monte Carlo simulation [64] and utilized the Latin Hypercube sampling method to ensure and show the ranges of parameters. A variance-based method was used to complete SA. The main purpose is to identify the most influential parameters and support decision making.

W. Tian [65] introduces the typical steps for a sensitivity analysis in a building performance analysis. The author illustrates sensitivity analysis methods in detail. These methods include local sensitivity analyses and global sensitivity analyses. In addition, the author recommends two programs: Simlab and R. These two programs are free and contain several sensitivity analysis methods. $R$ also has many functional sensitivity packages for sensitivity analyses in different model conditions. In similar research on the sensitivity analysis process, P. Heiselber et al. [66] mentioned a sensitivity analysis and screening method aimed at the early design stages of building design. The article illustrated the sensitivity analysis procedure in detail and utilized the BE06 software to complete the energy simulation. A.T. Nguyen and S. Reiter [67] compare nine types of sensitivity analysis methods through building energy simulation, i.e., three benchmark models and two real-world building models. After the comparison, they give the ranking of these nine methods in terms of variable importance, variable sensitivity indices, interaction among variables, and computational cost. Additionally, the authors illustrate the adaptation conditions of these nine methods. T. Østergård et al. [68] mentioned a series of sensitivity analysis techniques for informed early building design by exploring a multidimensional design space. They used a detailed Monte Carlo simulation in an iterative design to explore a global design space. The method of Morris and Variance-based methods were used to explore parametric sensitivities. The authors built a meta-model for a quantitative sensitivity analysis that can estimate how an input change influences multiple outputs in a global design space.

There are many other studies about sensitivity analyses. For example, J. Yang [69] researched monitor convergence and estimation uncertainty with respect to five sensitivity analysis techniques using two methods. In addition, F. Pianosi et al. [70] presented a review of the sensitivity analysis of environmental models. They provided a review of global sensitivity analyses and methods' relative 
model identification and application aspects, conducted a systematic classification of commonly used SA methods and provided guidelines for practical application of the SA method. J.S. Hygh et al. [71] analyzed parameter sensitivity for cooling, heating, and total load by constructing a multivariate linear regression. They advanced the parameter of standardized regression coefficients to drive energy performance design, which can be treated as a design parameter directly. C. Struck et al. [72] conducted an investigation of an option space's experience value (size, character, and content) in conceptual stages and provided uncertainty and sensitivity analyses for six building variables. For each variable, they listed the mean and standard deviation of the basic effects and drew variable regression lines of cooling demand. This regression line can show the strength of correlation between variables and a performance indicator.

\subsubsection{Parametric Analysis in Simulation Tools}

In the previous software descriptions, there are many tools with a parametric analysis function-for example, DesignBuilder. DesignBuilder's new version has the parametric analysis block including v4. and v5. A. Vartholomaios [73] conducted a study based on DesignBuilder 4.6; the author examined urban morphological parameters' influence on typical apartment energy consumption in the city of Thessaloniki in Greece, which has a Mediterranean climate requiring both cooling and heating. The article studied three types of urban typologies and five building geometry parameters. After several cycles of parameter simulation and identification of the input parameters' energy efficiency, the authors finally concluded two methods for low energy consumption. In addition, the OpenStudio simulation package has an independent tool for parametric analysis. Coupling the OpenStudio plugin for SketchUp and the OpenStudio Application, a parametric analysis process can be realized [9].

A "sensitivity tool" can help identify the degree of sensitivity of different parameters to energy in HTB2 [12]. There is a visible window about sensitivity simulation [74], which can display the simulation result directly after changing combinations of different parameters. Architects will find the best combination through this window. Sefaira's web APP [34] can analyze parameters and even several in parallel with the aid of cloud computing. jEPlus [37] is a relatively more specialized parametric analysis tool that can help with a parametric analysis and optimization in large-scale design work and build millions of simulation cases in only a few minutes. G.C. Rodríguez et al. [46] proposed a solution method for UA and SA in building energy simulations using macro parameters with jEPlus. They defined a detailed model in EnergyPlus and then defined uncertainties about input parameters by utilizing probability distributions. After creating a Latin Hypercube Sample from the input parameters, software jEPlus will run a simulation and obtain the results. Researchers will aggregate macro parameters, which affect the output, for each simulated sample. Additionally, a regression model can help calculate the sensitivity index for the macro parameters, which is helpful for the identification of the parameters' influence in outputs. Similarly, E. Naboni et al. [75] presented a parametric simulation workflow based on cloud computing through coupling jEPlus, OpenStudio, a web-based platform, and the Protovis visualization tool. In this process, a parametric study is defined by jEPlus, and a parametric simulated execution is conducted by jEPlus-VenusC.

iDbuild [48] is a goal-oriented parametric analysis tool that illustrates the effect of different parameters and parameter combinations for multiple building performances including indoor temperature, air quantity, and indoor daylight. S. Petersen and S. Svendsen [76] used iDbuild's parametric analysis function for predictive control of building system operation in the early stages of building design. Parametric analyses will automatically adapt to the configuration of a building control system. Moreover, this tool can help architects obtain a whole-year performance analysis for a suggested control system with no extra time consumed.

Parametric analysis tools and functional blocks are summarized in Table 3. Parametric analysis functional blocks were added to simulation tools to support whole lifecycle design, which improves the availability for decision making in the early design stages. 
Table 3. The software comparison in parametric analyses.

\begin{tabular}{|c|c|c|c|}
\hline Software & $\begin{array}{l}\text { Parametric Analysis } \\
\text { Block }\end{array}$ & Simulation Engine & Illustration \\
\hline DesignBuilder & Parametric Analysis & E+/Radiance & $\begin{array}{l}\text { No more than two variables and two } \\
\text { objective functions in one simulation. }\end{array}$ \\
\hline OpenStudio & Parametric Analysis Tool & E+/Radiance & $\begin{array}{l}\text { Allowing multiple design options to be } \\
\text { simulated and compared. }\end{array}$ \\
\hline HTB2 & Sensitivity Analysis & Own engine & $\begin{array}{l}\text { There will be an analysis chart of the } \\
\text { multiple variables' influence for energy. } \\
\text { Multiple combinations' energy } \\
\text { consumption will be displayed in a } \\
\text { sensitivity tool window. }\end{array}$ \\
\hline Sefaira & Web APP & E+ & $\begin{array}{l}\text { It can analyze and compare the energy } \\
\text { and daylight influence for different } \\
\text { variables. }\end{array}$ \\
\hline jEPlus & jEPlus (UA/SA) & $\mathrm{E}+$ & $\begin{array}{l}\text { It could complete large-scale and } \\
\text { in-depth parametric analysis } \\
\text { homework. }\end{array}$ \\
\hline iDBuild & iDBuild & Building Calc; Light Calc & $\begin{array}{l}\text { The tool could analyze parameters and } \\
\text { combinations based on the performance } \\
\text { destination. }\end{array}$ \\
\hline ZEBO & Sensitivity analysis & $\mathrm{E}+$ & $\begin{array}{l}\text { It can analyze and confirm the } \\
\text { influencing parameters and even their } \\
\text { ranges in the early stage, which is } \\
\text { energy and thermal comfort oriented. }\end{array}$ \\
\hline Riuska & $\begin{array}{l}\text { Sensitivity analysis } \\
\text { Uncertainty analysis }\end{array}$ & DOE-2 & $\begin{array}{l}\text { This tool integrated uncertainty } \\
\text { analysis and sensitivity analysis into a } \\
\text { standalone application. }\end{array}$ \\
\hline
\end{tabular}

\subsection{Optimization}

Optimization is an optimal design-option searching process based on a computational assistant technique. Hundreds of articles can be found in the science search engine "ScienceDirect" with the keyword "optimization". A review [26] introduced the conditions for optimization in building performance simulation. There is a tendency to move from a single-objective to multi-objective in optimization. However, most optimization tools are restricted to two objectives because of technique localization. Because of different objective orientations, the greatest obstacle of optimization is simulation time, which involves much calculation and time cost. This approach might be impractical for early design simulations. However, a more advanced technique can enhance velocity and even optimize in real time. Possibilities include, e.g., parallel computing, cloud computing, and meta-models. Currently, the most popular algorithms in optimization are the genetic and particle swarm optimization algorithms. However, other algorithms also exist for optimization, for example, the quasi-steady-state method [77]. Different optimization tools have the same goal—to find the most trade-off alternatives. The typical optimization method will analyze all of the possible alternatives' performances. Moreover, a full factorial plan might even be developed to simulate all available options. However, analyzing trade-off methods consumes much time, a reason to develop a genetic algorithm to increase the speed of alternative simulations [47].

\subsubsection{Literature Reviews about Optimization}

L. Junghans [78] introduced a fast calculating optimization method for use in the early design stage-Climate Surface Method (CSM) — combined with the equi-marginal building optimization method. The advantages of this method are that it can realize the entire building's optimization with a fast calculation speed and high accuracy. Researchers compared CSM and EnergyPlus on 
lifecycle cost. The result shows the CSM simulation speed is 41 times faster than EnergyPlus under the premise of higher accuracy. A. Buonomano et al. [79] raised a maximum primary energy value as an optimization function for a net zero energy building's energy and economic analysis using tool DETECt2.2. This tool can integrate multiple innovative technologies, such as PhotoVoltaic. The authors explored 18 facade parameter rational ranges through parametric analysis and conducted parameter optimization simulations of the most recommended value of each facade parameter. W. Wang et al. [80] applied multi-objective genetic algorithms for cost-effective green building design. They raised two types of variables in building design — discrete and continuous-and identified variable constraints according to parametric types. Lifecycle cost and lifecycle environmental impact were selected as the two objective functions to realize multi-objective optimization. T.M. Echenagucia et al. [81] used the NSGA-II algorithm to explore energy efficient envelope configuration in an open space office building. The NSGA-II algorithm is a multi-objective genetic algorithm; NSGA means Non-Dominated Sorting Genetic Algorithm. Alternatives of envelope configuration were explored in the Pareto front method, i.e., alternatives in suburban and urban contexts.

\subsubsection{Optimization in Simulation Tools}

Optimization blocks and optimization tools are mentioned in this part and summarized in Table 4.

Table 4. The software comparison in optimization.

\begin{tabular}{|c|c|c|c|c|}
\hline \multicolumn{2}{|c|}{ Software } & \multirow{3}{*}{$\begin{array}{l}\text { Optimization Block } \\
\text { Galapagos/Octopus } \\
\text { (coupling simulation) }\end{array}$} & \multirow{3}{*}{$\begin{array}{c}\text { Simulation Engine } \\
\text { E+/OpenStudio } \\
\text { Radiance/DAYSIM } \\
\text { Viper/DIVA } \\
\end{array}$} & \multirow{3}{*}{$\begin{array}{l}\text { Illustration } \\
\text { Coupling with a genetic algorithm block to } \\
\text { realize optimization in energy daylighting and } \\
\text { other building performance. }\end{array}$} \\
\hline \multirow[t]{2}{*}{ Grasshopper } & $\begin{array}{l}\text { Honeybee } \\
\text { and Ladybug }\end{array}$ & & & \\
\hline & IEC bear & & & \\
\hline \multicolumn{2}{|c|}{ DesignBuilder } & Optimization & E+/ Radiance & $\begin{array}{l}\text { It can optimize multiple variables and find the } \\
\text { optimal combination under two objective } \\
\text { functions }\end{array}$ \\
\hline \multicolumn{2}{|c|}{ BEopt } & BEopt & DOE-2/TRNSYS & $\begin{array}{l}\text { It can find the most cost-effective overall } \\
\text { energy saving strategy portfolio }\end{array}$ \\
\hline \multicolumn{2}{|c|}{ GenOpt } & GenOpt & E+/TRNSYS/DOE2 etc. & $\begin{array}{l}\text { Professional optimization software, allowing } \\
\text { local and global optimization and parallel } \\
\text { simulation }\end{array}$ \\
\hline \multicolumn{2}{|c|}{ jEPlus (jESS) } & jEPlus & E+ & Coupling with jESS to realize optimization \\
\hline
\end{tabular}

On the Grasshopper platform plugin for Rhino, there is a genetic algorithm block named Galapagos that can realize optimization for any reasonable objective function if users define the necessary variables constraints and objectives. However, when Galapagos couples with HoneyBee and LadyBug [23] for energy or daylight optimization, a lot of time and many calculations will be needed. In contrast with Galapagos' single-objective optimization, Octopus is another optimizer on the grasshopper platform for multi-objective optimization. K. Konis et al. [82] illustrated a passive performance optimization framework in the early design stages to enhance natural lighting, solar control, and the natural ventilation strategies' performance. This framework contains six steps: site, geometry, daylighting, thermal energy, visualization, and optimization. The entire process is completed in the grasshopper platform. Daylighting is calculated by HoneyBee and Radiance, thermal energy is calculated by EnergyPlus, and optimization is realized by Octopus. Thus, a passive performance-based optimization process can be achieved in one software platform, ensuring the continuity of building design. In addition, I. Anton and D. Tănase [83] used a pre-rationalization method to create a building skin on the grasshopper platform and searched for an optimal building form following the minimum energy consumption and maximum shading area criteria with the help of Galapagos. A. Zhang et al. [84] and H. Samuelson et al. [85] explored building design alternatives on the Rhino and Grasshopper platform. They used SA or an optimization method to adjust design parameter combinations to meet certain performance goals. 
Furthermore, there are specialized optimization tools such as BEopt [86] and GenOpt [87]. BEopt is a building energy optimization software product primarily aimed at residential building design, helping researchers and energy analysts to develop whole-building energy strategy options that are the most cost-effective based on optimization. It can realize detailed performance-based analysis and optimization according to the specified building's characteristics, such as sizes, occupancy, vintage, location, and utility rates. R. Anderson and C. Christensen [36] described the working theory of BEopt, which employs the Sequential search method to search all of the design elements, including, for example, wall types, roof types, glass types, and HVAC types. After the simulation, it can assess all of the possible options about the envelope and equipment and find the most cost-effective combination for the new building design strategy. This software calculates the simulation using current simulation engines; most users can build an energy model based on DOE-2, calculating the PV array and output of the solar thermal system based on TRNSYS. Alternatively, BEopt's users can use EnergyPlus to simulate energy. BEopt calculates and optimizes based on three input aspects: geometry, parametric option, and site condition. However, it has constraints in geometry modeling. For example, the wall must be homogeneous; windows are always arranged at the same height, which users cannot change; and some building's shapes cannot be realized. This software might have some inconvenience in operation, with one to four hours required for one complete single optimization.

GenOpt is another optimization tool based on user-defined objective functions. GenOpt has a library with local and global multi-dimensions, a one-dimension optimization algorithm, and even a parametric calculation algorithm. It can achieve multiple automated simulation parallel runs without user settings when there are multiple CPUs [88]. After changing configuration files, this tool can couple with outside simulation engines easily, e.g., EnergyPlus, TRNSYS, Dymola, IDA-ICE, DOE-2, TRACE and even your own simulation program files based on I/O [52]. However, this tool requires that users understand optimization theory and have JAVA skills because users must add their own programmed genetic algorithm to the GenOpt library. Therefore, relatively speaking, DesignBuilder's optimization module might be more suitable for architects because of its concise user interface and easy-to-learn operation process.

\subsection{Limitations of Simulation Tools}

A good BPS tool is expected to maintain the continuity of the design process. In a traditional simulation operation, integrated design alternatives with energy information about structure, materials, and equipment frequently require much time to achieve one integrated simulation. Thereafter, the comparison of multiple alternatives will help the architect to make decisions and undertake strategies for his or her building. However, for the most part, people only want a simulation result and the amount of energy saving. Similarly, fewer studies examine this process to build a more energy-saving building. In the early design stage, with rapid changes and jumps in design thinking, architects must determine the building's block, size, and even parameters such as window wall rate. Therefore, a practical and suitable BPS tool needs a rapid calculation speed to assist the architect's work at this stage. An advanced simulation technique coupled with an optimizer tends to be time-consuming [89]. To enhance the simulation speed in the early design stage, many methods are illustrated in the literature, for example, meta-models [89,90], cloud computing [75] and parallel computing. Coupled with several techniques, a run-time simulation will be applied in the early design stage.

Building performance simulation tools can be divided into two categories: physical calculation models and statistical calculation models [91]. The physical calculation model can simulate the entire building performance with a high accuracy, e.g., Ecotect applied in the conceptual stage. The statistical calculation model will calculate with experience values instead of a physical calculation. Therefore, it has few inputs and a fast calculation speed. However, it yields only a rough estimation, which can support decision making for building performance. The disadvantage of the statistical calculation model is that it will lose its effect when default variable parameters change, e.g., loads and orientation. 
A meta-model is a mathematical method that illustrates relationships between inputs and outputs for easy and fast computing [26]. Such models are available in optimization [89], parametric analysis [92], and run-time simulation. J. Hester et al. [92] introduce a novelty regression-based energy meta-model method for designing a single residential building in an early design stage. This model can provide flexibility and low detail conceptual design to realize the decision-support function through a quantitative probability analysis. A Monte Carlo simulation can provide an uncertainty analysis and a sensitivity analysis and can diagnose the most influential parameter in energy consumption and the maximum contribution rate to the meta-model. Thus, the complexity of an energy model can be reduced approximately by $90 \%$. P. Geyer and A. Schlüter [90] mentioned multiple types of meta-models, including Kriging, other Radial Basic Functions, Support Vector Regression, Neuronal Networks and Response Surface Method [8]. To solve numerous design variables and time-consuming questions in a performance-based design process, the authors stressed the Response Surface Method meta-model. This method can react rapidly to the performance model and contain all of the design space knowledge.

In addition, many researchers $[68,71,93]$ present statistical calculation models in the early design stages to guarantee a smoother, performance-based design process. H. Son and C. Kim [94] organized a statistical model to predict the costs and schedules of green building in the early design stages. They used the Relief- $W$ variable selection method to choose predicted parameters from 53 certified green building data and then constructed a prediction model based on the predicted variables for performance prediction. Aiming at early commercial building design, S. Asadi et al. [93] organized a new model to predict and quantify energy consumption. They used the eQUEST [29] tool, the DOE-2 tool and Monte Carlo simulation to create a comprehensive dataset covering all of the design parameters. Then, they built a series of regression models based on the simulation results. These models can complete the prediction of energy consumption in a variety of conditions. This mathematical method greatly improves the calculation speed of models. It is also beneficial for decision making. T. Østergård et al. [64] applied a probability density function, Monte Carlo simulation, and Monte Carlo filtering to identify the best ranges of influential input parameters. Holistic scoring functions were built to evaluate the synthesized building performance. A case study of this stochastic and holistic method showed that it is suitable for decision making in early design stages with fast computing to realize more solution space exploration and good building performance.

\section{Summary Analysis and Conclusions}

\subsection{Summary Analysis}

This article focused on arranging categories of simulation tools and BPS tool illustrations in practical applications. According to these tools' organization framework, BPS tools were classified into three categories. The first one consists of simulation plugins for design tools, which include the design tools' advantages in design-for example, a massive customer base, non-essential remodeling, and familiar design environment. A typical tool is Sefaira, which developed plugins for SketchUp and Revit and coupled them with cloud technique and parametric analysis to enhance this tool's application, even realizing run-time simulation feedback. The second category is third-party simulation tools based on an authoritative simulation engine, e.g., EnergyPlus. This type of tool usually has a geometry user interface or friendly input interface that is easy to learn and use and more available for non-engineering personnel. The third category is a self-governing simulation tool that includes its own geometry user interface and simulation method. However, more work is needed in proving its results' accuracy.

Through the illustration of simulation tools' functions and practical applications, this paper created four criteria to identify the availability of tools in the early stage of building design. A pre-supported simulation tool must be an architect-friendly tool that supports simulation feedback with few inputs. It may also support UA and SA and the simultaneous comparison of multiple 
design options. Thereafter, discussions on topics that are already maturely applied in existing tools and limitations on simulation tools were presented. Many skills are highly used with modern tools to achieve additional design and simulated operations, i.e., building templates, building databases, sensitivity analyses, uncertainty analyses, and optimization are quite hot topics in simulation. Most BPS tools use their own database or use an outside database, which is useful in the whole-building design stages. Based on the tools' application ranges and regions, local common building information about materials, construction and facilities are added to the database to construct an energy model. A database can almost determine a tool's application level. Therefore, an accurate database is helpful to enhance the tool's application range. Parametric analysis (UA or SA) and optimization are popular methods for an architect to make decisions in early design stages. Currently, the parametric analysis is more suitable in early decision making for its lesser amount of calculation. Parametric analysis can help the architect to measure different variables' influence on energy and determine parameter ranges and even variable combinations. An optimization block can provide a series of optimal alternatives automatically under an objective function. However, a significant amount of time is needed for optimization because of its large number of calculations. More techniques such as cloud computing and parallel computing were applied in simulation to increase simulation speed. Particularly in the early design stage, rapid simulation can promise the continuity of design work and thoughts.

\subsection{Conclusions}

The categories of simulation tools reflect organizational structure. They also support key aspects of professional practice. Plugins for design tools can permit the architect to realize performance weights in the original familiar design environment. This type can also couple with mature engines, ensuring accuracy. Relative to self-governing tools and engines' GUIs, the organization of plugins will have a wider use in the future, aimed at architects in early design stages. For instance, SketchUp owns relatively more plugins in response to the relatively large use of the tool as a foundation. However, Revit owns a better-integrated platform based on design tools for Autodesk and this platform can realize continuity design and smooth simulation feedback. Additionally, worthy of mention is the Rhino and Grasshopper platform. It gained more users among architects when parametric design became popular in architecture design. Different from SketchUp and Revit, the Rhino and Grasshopper platform is more open for non-experts to extend its functions through simple code learning according to their own requirements. However, this platform is not mature enough, and lots of problems may appear while operating it, especially for beginners. To support decision making in early design stages, advanced techniques applied in plugins for a design tool can be the solution in the future. More effort should be expended on real-time feedback and more-convenient trade-off methods to improve the realization in the design environment through plugin development.

Funding: This work was funded by the National Key Research and Development Program of China (Grant No. 2016YFC0700201) and the National Natural Science Foundation of China (Grant No. 51338006).

Acknowledgments: We would like to thank the School of Architecture for providing equipment support and teaching resources from the International Engineering Institute.

Conflicts of Interest: The authors declare no conflict of interest.

\section{References}

1. Reichard, G.; Papamichael, K. Decision-making through performance simulation and code compliance from the early schematic phases of building design. Autom. Constr. 2005, 14, 173-180. [CrossRef]

2. Ritter, F.; Geyer, P.; Borrmann, A. Simulation-based decision-making in early design stages. In Proceedings of the 32nd CIB W78 Conference, Eindhoven, The Netherlands, 27-29 October 2015.

3. De Wilde, P. Computational Support for the Selection of Energy Saving Building Components. Ph.D. Thesis, Delft University of Technology, Delft, The Netherlands, 2004.

4. Attia, S.; Gratia, E.; de Herde, A.; Hensen, J.L.M. Simulation-based decision support tool for early stages of zero-energy building design. Energy Build. 2012, 49, 2-15. [CrossRef] 
5. Lam, K.P.; Wong, N.H.; Mahdavi, A.; Chan, K.K.; Kang, Z.; Gupta, S. SEMPER-II: An internet-based multi-domain building performance simulation environment for early design support. Autom. Constr. 2004, 13, 651-663. [CrossRef]

6. Seyis, S.; Ergen, E. A decision making support tool for selecting green building certification credits based on project delivery attributes. Build. Environ. 2017, 126, 107-118. [CrossRef]

7. OpenStudio I OpenStudio. Available online: https:/ / www.openstudio.net/ (accessed on 12 July 2017).

8. Building Energy Software Tools Directory. Available online: https://www.buildingenergysoftwaretools. com/software/OpenStudio (accessed on 15 July 2017).

9. Macumber, D.L.; Ball, B.L.; Long, N.L. A graphical tool for cloud-based building energy simulation. In Proceedings of the 2014 ASHRAE/IBPSA-USA Building Simulation Conference, Atlanta, GA, USA, 10-12 September 2014; pp. 87-94.

10. Picco, M.; Lollini, R.; Marengo, M. Towards energy performance evaluation in early stage building design: A simplification methodology for commercial building models. Energy Build. 2014, 76, 497-505. [CrossRef]

11. Boxer, E.; Henze, G.P.; Hirsch, A.I. A model-based decision support tool for building portfolios under uncertainty. Autom. Constr. 2017, 78, 34-50. [CrossRef]

12. Jones, P.; Lannon, S.; Li, X.; Bassett, T.; Waldron, D. Intensive building energy simulation at early design stage. In Proceedings of the 13th Conference of the International Building Performance Simulation Association (BS 2013), Le Bourget Du Lac, France, 25-30 August 2013; pp. 862-869.

13. Jones, P.; Li, X.; Coma, E.; Patterson, J. The SOLCER Energy Positive House: Whole System Simulation; Welsh School of Architecture, Cardiff University: Cardiff, UK, 2017.

14. Alexander, D.K.; Mylona, A.; Jones, P.J. The simulation of glazing systems in the dynamic thermal model HTB2. In Proceedings of the Ninth International IBPSA Conference, Montréal, QC, Canada, 15-18 August 2005.

15. IES VE Building Design Software. Available online: https://www.green-buildings.com/articles/ies-vebuilding-design-software/ (accessed on 4 August 2017).

16. Green Building Studio. Available online: https://gbs.autodesk.com/GBS/ (accessed on 6 August 2017).

17. Advanced Energy Analysis with Green Building Studio DOE2 and EnergyPlus support. Available online: http://autodesk.typepad.com/bpa/2013/03/advanced-energy-analysis-with-green-buildingstudio-doe2-and-EnergyPlus-support.html (accessed on 16 August 2017).

18. Lin, S.-H.E.; Gerber, D.J. Designing-in performance: A framework for evolutionary energy performance feedback in early stage design. Autom. Constr. 2014, 38, 59-73. [CrossRef]

19. Nembrini, J.; Samberger, S.; Labelle, G. Parametric scripting for early design performance simulation. Energy Build. 2014, 68, 786-798. [CrossRef]

20. Dynamo BIM. 2017. Available online: http:/ / dynamobim.org/ (accessed on 8 August 2017).

21. Computational Design Software, Buildings-Generative Components. 2017. Available online: https://www. bentley.com/en/products/product-line/modeling-and-visualization-software/generativecomponents (accessed on 8 August 2017).

22. Elbeltagi, E.; Wefki, H.; Abdrabou, S.; Dawood, M.; Ramzy, A. Visualized strategy for predicting buildings energy consumption during early design stage using parametric analysis. J. Build. Eng. 2017, 13, 127-136. [CrossRef]

23. Ladybug Tools-Grasshopper. 2017. Available online: http://www.grasshopper3d.com/group/Ladybug (accessed on 7 August 2017).

24. National Renewable Energy Laboratory, OpenStudio. 2017. Available online: https://www.OpenStudio.net/ (accessed on 12 July 2017).

25. Qingsong, M.; Fukuda, H. Parametric office building for daylight and energy analysis in the early design stages. Procedia-Soc. Behav. Sci. 2016, 216, 818-828. [CrossRef]

26. Østergård, T.; Jensen, R.L.; Maagaard, S.E. Building simulations supporting decision making in early design-A review. Renew. Sustain. Energy Rev. 2016, 61, 187-201. [CrossRef]

27. Doelling, M.C. Space-based thermal metrics mapping for conceptual low-energy architectural design. In Proceedings of the Building Simulation and Optimization (BSO14), London, UK, 23-24 June 2014.

28. Lauridsen, P.K.B.; Petersen, S. Integrating indoor climate, daylight and energy simulations in: Parametric models and performance-based design. In Proceedings of the 3rd International Workshop on Design in Civil and Environmental Engineering, Kongens Lyngby, Denmark, 21-23 August 2014; pp. 111-118. 
29. eQUEST. Available online: http:/ / www.doe2.com/equest/ (accessed on 15 August 2017).

30. Jokela, M.; Keinänen, A.; Lahtela, H.; Lassila, K. Integrated Building Simulation Tool-Riuska; Insinööritoimisto Olof Granlund Oy: Helsinki, Finland, 1997.

31. EE4 CBIP/Best Directory-Building Energy Software Tools. Available online: https://www. buildingenergysoftwaretools.com/software/ee4-cbip (accessed on 5 September 2017).

32. TRANSOL-Solar Thermal Energy/Best Directory. Available online: https://www. buildingenergysoftwaretools.com/software/transol-solar-thermal-energy (accessed on 5 September 2017).

33. Design Builder Software. Available online: https://www.DesignBuilder.co.uk/ (accessed on 8 August 2017).

34. Sefaira, Sefaira. 2015. Available online: http://Sefaira.com (accessed on 8 July 2011).

35. Pelken, P.M.; Zhang, J.; Chen, Y.; Rice, D.J.; Meng, Z.; Semahegn, S.; Gu, L.; Henderson, H.; Feng, W.; Ling, F. “Virtual Design Studio"-Part 1: Interdisciplinary design processes. Build. Simul. 2013, 6, 235-251. [CrossRef]

36. Anderson, R.; Christensen, C. Analysis of Residential System Strategies Targeting Least-Cost Solutions Leading to Net Zero Energy Homes. ASHRAE Trans. 2006, 112, 330-341.

37. jEPlus|Best Directory-Building Energy Software Tools. Available online: https://www. buildingenergysoftwaretools.com/software/jeplus (accessed on 8 August 2017).

38. N++-ExpertApp. Available online: http://expertapp.com/npp.php (accessed on 9 August 2017).

39. EFEN/Best Directory-Building Energy Software Tools. Available online: https://www. buildingenergysoftwaretools.com/software/efen (accessed on 12 August 2017).

40. AECOsim Energy Simulator-Bentley Systems. Available online: https://www.bentley.com/zh/products / product-line/building-design-software/aecosim-energy-simulator (accessed on 8 September 2017).

41. Hevacomp Simulator V8i. Available online: http://www.directindustry.cn.com/prod/bentley-systemseurope-b-v/product-28711--512443.html (accessed on 10 September 2017).

42. GEnergy/Best Directory-Building Energy Software Tools. Available online: https://www. buildingenergysoftwaretools.com/software/genergy (accessed on 2 October 2017).

43. Simergy: Practitioner-Oriented Graphical User Interface for EnergyPlus CR-2998. Available online: https: / /ipo.lbl.gov/lbnl2998/ (accessed on 10 September 2017).

44. FineGREEN/Best Directory-Building Energy Software Tools. Available online: https://www. buildingenergysoftwaretools.com/software/finegreen (accessed on 2 October 17).

45. Zhang, A.; Bokel, R.; van den Dobbelsteen, A.; Sun, Y.; Huang, Q.; Zhang, Q. An integrated school and schoolyard design method for summer thermal comfort and energy efficiency in Northern China. Build. Environ. 2017, 124, 369-387. [CrossRef]

46. Rodríguez, G.C.; Andrés, A.C.; Muñoz, F.D.; López, J.M.C.; Zhang, Y. Uncertainties and sensitivity analysis in building energy simulation using macroparameters. Energy Build. 2013, 67, 79-87. [CrossRef]

47. Lara, R.A.; Naboni, E.; Pernigotto, G. Optimization Tools for Building Energy Model Calibration. Energy Procedia 2017, 111, 1060-1069. [CrossRef]

48. Download iDbuild. Available online: http://www.iDbuild.dk/ (accessed on 11 August 2017).

49. Petersen, S.; Svendsen, S.; Christoffersen, L.D. Simulation-Based Support for Integrated Design of New Low-Energy Office Buildings. Ph.D. Thesis, Technical University of Denmark, Department of Civil Engineering, Kgs. Lyngby, Denmark, 2011.

50. Nielsen, T.R. Simple tool to evaluate energy demand and indoor environment in the early stages of building design. Sol. Energy 2005, 78, 73-83. [CrossRef]

51. Petersen, S.; Momme, A.J.; Hviid, C.A. A simple tool to evaluate the effect of the urban canyon on daylight level and energy demand in the early stages of building design. Sol. Energy 2014, 108, 61-68. [CrossRef]

52. Petersen, S.; Svendsen, S. Method and simulation program informed decisions in the early stages of building design. Energy Build. 2010, 42, 1113-1119. [CrossRef]

53. Ochoa, C.E.; Capeluto, I.G. Advice tool for early design stages of intelligent facades based on energy and visual comfort approach. Energy Build. 2009, 41, 480-488. [CrossRef]

54. Bustamante, W.; Uribe, D.; Vera, S.; Molina, G. An integrated thermal and lighting simulation tool to support the design process of complex fenestration systems for office buildings. Appl. Energy 2017, 198, 36-48. [CrossRef]

55. Oh, J.H.; Sung, J.E.; Kim, S.S. Development of window design guideline and tools for early stage decision support. Energy Procedia 2017, 122, 991-996. [CrossRef] 
56. Urban, B. The MIT Design Advisor-a fast, simple tool for energy efficient building design. In Proceedings of the SimBuild 2006, Cambridge, MA, USA, 2-4 August 2006; Massachusetts Institute of Technology: Cambridge, MA, USA, 2006. Available online: http:/ / ceae.colorado.edu/ibpsa/ocs/viewabstract.php?id= $186 \& c f=2$ (accessed on 15 August 2017).

57. Urban, B.; Glicksman, L. A Rapid Building Energy Model and Interface for Non-Technical Users. In Proceedings of the 10th ORNL Thermal Performance of the Exterior Envelopes of Whole Buildings International Conference, Clearwater, FL, USA, 5-9 October 2012.

58. Wen, L.; Hiyama, K. A review: Simple tools for evaluating the energy performance inearly design stages. Procedia Eng. 2016, 146, 32-39. [CrossRef]

59. Attia, S.; Beltrán, L.; de Herde, A.; Hensen, J. Architect friendly: A comparison of ten different building performance simulation tools. In Proceedings of the 11th International IBPSA Conference, Glasgow, UK, 27-30 July 2009.

60. Draper, D. Assessment and propagation of model uncertainty. J. R. Stat. Soc. Ser. B 1995, 57, 45-97.

61. Lolli, N.; Fufa, S.M.; Inman, M. A parametric tool for the assessment of operational energy use, embodied energy and embodied material emissions in building. Energy Procedia 2017, 111, 21-30. [CrossRef]

62. Chen, J.; Augenbroe, G.; Wang, Q.; Song, X. Uncertainty analysis of thermal comfort in a prototypical naturally ventilated office building and its implications compared to deterministic simulation. Energy Build. 2017, 146, 283-294. [CrossRef]

63. Shen, H.; Tzempelikos, A. Sensitivity analysis on daylighting and energy performance of perimeter offices with automated shading. Build. Environ. 2013, 59, 303-314. [CrossRef]

64. Østergård, T.; Maagaard, S.E.; Jensen, R.L. A stochastic and holistic method to support decision-making in early building design. In Proceedings of the 14th Conference of International Building Performance Simulation Association (BS 2015), Hyderabad, India, 7-9 December 2015.

65. Tian, W. A review of sensitivity analysis methods in building energy analysis. Renew. Sustain. Energy Rev. 2013, 20, 411-419. [CrossRef]

66. Heiselberg, P.; Brohus, H.; Hesselholt, A.; Rasmussen, H.; Seinre, E.; Thomas, S. Application of sensitivity analysis in design of sustainable buildings. Renew. Energy 2009, 34, 2030-2036. [CrossRef]

67. Nguyen, A.T.; Reiter, S. A performance comparison of sensitivity analysis methods for building energy models. Build. Simul. 2015, 8, 651-664. [CrossRef]

68. Østergård, T.; Jensen, R.L.; Maagaar, S.E. Early Building Design: Informed decision-making by exploring multidimensional design space using sensitivity analysis. Energy Build. 2017, 142, 8-22. [CrossRef]

69. Yang, J. Convergence and uncertainty analyses in Monte-Carlo based sensitivity analysis. Environ. Model. Softw. 2011, 26, 444-457. [CrossRef]

70. Pianosi, F.; Beven, K.; Freer, J.; Hall, J.W.; Rougier, J.; Stephenson, D.B.; Wagener, T. Sensitivity analysis of environmental models: A systematic review with practical workflow. Environ. Model. Softw. 2016, 79, 214-232. [CrossRef]

71. Hygh, J.S.; DeCarolis, J.F.; Hill, D.B.; Ranjithan, S.R. Multivariate regression as an energy assessment tool in early building design. Build. Environ. 2012, 57, 165-175. [CrossRef]

72. Struck, C.; de Wilde, P.J.C.J.; Hopfe, C.J.; Hensen, J.L.M. An investigation of the option space in conceptual building design for advanced building simulation. Adv. Eng. Inform. 2009, 23, 386-395. [CrossRef]

73. Vartholomaios, A. A parametric sensitivity analysis of the influence of urban form on domestic energy consumption for heating and cooling in a Mediterranean city. Sustain. Cities Soc. 2017, 28, 135-145. [CrossRef]

74. Jones, P.; Lannon, S.; Li, X. Development of a Building Energy 'Sensitivity' Tool to Inform Early-Stage Design Decisions and its Application in China. In Proceedings of the 8th International Symposium on Heating, Ventilation and Air Conditioning; Lecture Notes in Electrical Engineering; Springer: Berlin/Heidelberg, Germany, 2014; Volume 261.

75. Naboni, E.; Zhang, Y.; Maccarini, A.; Hirsch, E.; Lezzi, D. Extending the Use of Parametric Simulation in Practice through a Cloud Based Online Service. Available online: http:/ /www.ibpsa.org/proceedings / BSA2013/11.pdf (accessed on 10 October 2017).

76. Petersen, S.; Svendsen, S. Method for simulating predictive control of building systems operation in the early stages of building design. Appl. Energy 2011, 88, 4597-4606. [CrossRef]

77. Negendahl, K.; Nielsen, T.R. Building energy optimization in the early design stages: A simplified method. Energy Build. 2015, 105, 88-99. [CrossRef] 
78. Junghans, L. Improved fast calculating Climate Surface calculation method combined with multi-parameter building optimization for early design stages. Energy Procedia 2014, 57, 2005-2013. [CrossRef]

79. Buonomano, A.; de Luca, G.; Montanaro, U.; Palombo, A. Innovative technologies for NZEBs: An energy and economic analysistool and a case study of a non-residential building for theMediterranean climate. Energy Build. 2016, 121, 318-343. [CrossRef]

80. Wang, W.; Zmeureanu, R.; Rivard, H. Applying multi-objective genetic algorithms in green building design and optimization. Build. Environ. 2005, 40, 1512-1525. [CrossRef]

81. Echenagucia, T.M.; Capozzoli, A.; Cascone, Y.; Sassone, M. The early design stage of a building envelope: Multi-objective search through heating, cooling and lighting energy performance analysis. Appl. Energy 2015, 154, 577-591. [CrossRef]

82. Konis, K.; Gamas, A.; Kensek, K. Passive performance and building form: An optimization framework for early-stage design support. Sol. Energy 2016, 125, 161-179. [CrossRef]

83. Anton, I.; Tănase, D. Informed Geometries. Parametric Modelling and Energy Analysis in Early Stages of Design. Energy Procedia 2016, 85, 9-16. [CrossRef]

84. Zhang, A.; Bokel, R.; van den Dobbelsteen, A.; Sun, Y.; Huang, Q.; Zhang, Q. Optimization of thermal and daylight performance of school buildingsbased on a multi-objective genetic algorithm in the cold climate of China. Energy Build. 2017, 139, 371-384. [CrossRef]

85. Samuelson, H.; Claussnitzer, S.; Goyal, A.; Chen, Y. Parametric energy simulation in early design: High-rise residential buildings in urban contexts. Build. Environ. 2016, 101, 19-31. [CrossRef]

86. BEopt: Home. Available online: https://beopt.nrel.gov/features (accessed on 10 August 2017).

87. GenOpt/Best Directory-Building Energy Software Tools. Available online: https://www. buildingenergysoftwaretools.com/software/genopt (accessed on 18 August 2017).

88. Wetter, M. GenOpt_-A Generic Optimization Program. In Proceedings of the Seventh International IBPSA Conference, Rio de Janeiro, Brazil, 13-15 August 2001.

89. Eisenhower, B.; O’Neill, Z.; Narayanan, S.; Fonoberov, V.A.; Mezi'c, I. A methodology for meta-model based optimization in building energy models. Energy Build. 2012, 47, 292-301. [CrossRef]

90. Geyer, P.; Schlüter, A. Automated metamodel generation for Design Space Exploration and decision-making-a novel method supporting performance-oriented building design and retrofitting. Appl. Energy 2014, 119, 537-556. [CrossRef]

91. Schlueter, A.; Thesseling, F. Building information model based energy/exergy performance assessment in early design stages. Autom. Constr. 2009, 18, 153-163. [CrossRef]

92. Hester, J.; Gregory, J.; Kirchain, R. Sequential early-design guidance for residential single-family buildings using a probabilistic metamodel of energy consumption. Energy Build. 2017, 134, 202-211. [CrossRef]

93. Asadi, S.; Amiri, S.S.; Mottahedi, M. On the development of multi-linear regression analysis to assess energy consumption in the early stages of building design. Energy Build. 2014, 85, 246-255. [CrossRef]

94. Son, H.; Kim, C. Early prediction of the performance of green building projects using pre-project planning variables: Data mining approaches. J. Clean. Prod. 2015, 109, 144-151. [CrossRef]

(C) 2018 by the authors. Licensee MDPI, Basel, Switzerland. This article is an open access article distributed under the terms and conditions of the Creative Commons Attribution (CC BY) license (http://creativecommons.org/licenses/by/4.0/). 